\title{
High-value care programmes from the bottom-up... and the top-down
}

\author{
Christopher Moriates, ${ }^{1,2,3}$ Brian M Wong ${ }^{4,5,6}$
}

For numbered affiliations see end of article.

\section{Correspondence to}

Dr Christopher Moriates, 505 Parnassus Ave, M1287, San Francisco, CA 94143, USA; CMoriates@medicine.ucsf.edu

Accepted 15 December 2015 Published Online First 6 January 2016

\section{SLinked}

- http://dx.doi.org/10.1136/ bmjqs-2015-004546

CrossMark

To cite: Moriates $C$ Wong BM. BMJ Qual Saf 2016:25:821-823.
The introduction of high-value care into medical education is emerging as a global imperative. ${ }^{1}$ While delivering on the promise of 'best care at lower cost' will require major shifts at every level of the healthcare system, ${ }^{2}$ training the new pipeline of health professionals in both the ideals and the execution of high-value care remains a critical target for creating future change. ${ }^{3} 4$

Stinnett-Donnelly and colleagues describe a programme at their academic institution aimed at simultaneously reducing unnecessary or harmful care, improving patient experience and educating resident trainees about high-value care. ${ }^{5}$ Over the first two years of this comprehensive programme, this US academic medical centre (the University of Vermont) realised impressive reductions across dual-energy X-ray absorptiometry scans in non-elderly women, daily chest $\mathrm{X}$-rays in the intensive care unit and routine serum creatinine measurements in patients undergoing chronic dialysis. These interventions improved quality of care by eliminating wasteful tests and also resulted in measurable cost savings for the institution, estimated conservatively to be $\$ 326974$ thus far.

The resident physicians in this programme contributed insights on areas of waste, served as peer educators, and co-led projects-a strategy that the authors highlight as an effective 'bottom-up' approach. There is no doubt that this type of front-line engagement of learners is necessary to move high-value care initiatives forward, and likely was largely responsible for some of the early successes seen in this study. However, we note that, unlike some of our experiences with quality improvement (QI) and patient safety initiatives, garnering enthusiasm from residents for high-value care tends not to be challenging: talk to resident physicians about something like hand hygiene and it is difficult to generate much fanfare, but ask them about cutting out waste, and the ideas and energy seem to come flowing. Thus, bottom-up engagement may not actually be the hard part of implementing highvalue care initiatives. In fact, so much of what was done in the programme described by Stinnett-Donnelly and colleagues was top-down 'enabled', that we should not lose sight of the fact that organisational support is critical to the success of initiatives like the one described. ${ }^{5}$ We would like to reflect on several key ways that organisations can support high-value care projects, drawing on what was done by the group in Vermont, as well as looking to other examples.

\section{LEADERSHIP ENDORSEMENT AND SUPPORT}

In this study, senior leadership-from the president and chief executive officer on down-provided key support, sending a message that high-value care is a priority for the organisation. This endorsement is crucial to set the culture for improvement and also to avail necessary resources for successful project implementation. ${ }^{6}$ This creates a 'support spine' up the organisational chart, which authorises those on the front lines to pursue these goals and initiatives.

However, simply providing top-down proclamations or imperatives is also not sufficient to create change, as shown by the Graduate Medical Education leadership group at Johns Hopkins, which sent out emails to residency and fellowship directors asking them to identify one commonly used unnecessary or wasteful medical test or procedure, and received very limited responses to their requests. ${ }^{7}$ This poor response illustrates that institutional leaders must not only generate the will for change and clearly communicate the goals, but also ensure that teams have the necessary support and resources to enact the desired changes. ${ }^{8}$ 
In the Vermont example, ${ }^{5}$ by deploying project management, data analysis and electronic health record resources and support, senior leaders clearly backed up their stated endorsement of their organisational commitment towards high-value care with actual support to enable front-line teams to achieve success and project completion. Too often, senior leaders express support for a specific project or improvement goal, but do not provide concrete support to front-line staff .

\section{IDENTIFYING APPROPRIATE HIGH-VALUE CARE TARGETS}

Many of the project ideas in the Vermont programme came directly from clinicians. This local crowdsourcing method for identifying targets has proven to be an effective strategy, which one of us (CM) has also used to great effect in the Caring Wisely programme at the University of California, San Francisco. ${ }^{10}$ However, in addition to clinician-generated ideas, organisational leadership can and should help teams choose appropriate high-value care targets.

Many groups will naturally turn to the Choosing Wisely lists for identifying low-value practices. ${ }^{11} 12$ This is a great place to start, but we caution groups from relying solely on this approach. Not all Choosing Wisely targets will be applicable to local overuse practices, and not all local overuse practices will be found on a Choosing Wisely list. ${ }^{13-15}$ Furthermore, some of these national recommendations highlight lowfrequency overuse practices that may not be amenable to improvement, ${ }^{16} 17$ particularly when applied on a local scale. Organisational leaders can provide institutional data on utilisation patterns, variation and associated costs that can direct the choice of targets most likely to result in meaningful impact.

Stinnett-Donnelly and colleagues propose a framework for selecting targets that are non-controversial and evidence-based; easily measured electronically; and that lend themselves to interventions that would not increase physician workload and would lead to a "meaningful outcome that would add value (reduce harm, reduce cost, improve patient outcome or experience)". 5 These are useful criteria for identifying pragmatic targets that can lead to early wins, which are critical to generating long-lasting change. ${ }^{18}$

\section{INVESTING IN DATA INFRASTRUCTURE}

Obtaining institutional data in a timely manner-from basic metrics such as length of stay or readmission rates to more project-specific measures-presents problems for many QI projects. High-value care projects present additional challenges as they require investigating utilisation and cost data, which may be seen as more sensitive information for the institution, often leading to significant barriers. Institutions that have shown breakthrough leadership on implementing high-value care initiatives have invested significant resources in creating and validating data systems for measuring utilisation and costs. ${ }^{19} 20$ Bottom-up empowerment is unlikely to result in meaningful change without the organisational investment in data infrastructure and support.

In addition, there are some nuances around highvalue care data that clinicians and health system leaders should know about. For example, defining 'appropriateness' for a specific test or procedure can prove elusive. $^{21}$ We have found that rather than trying to determine appropriateness, it might be more feasible to combine a measure of global utilisation with a balancing measure that ensures we have not reduced appropriate care. Alternatively, teams can measure variation in utilisation patterns across groups of providers or clinical units, and demonstrate reductions in overall variation as an appropriate proxy in some situations. ${ }^{22}$

\section{THE IMPORTANCE OF FACULTY ENGAGEMENT}

Each of the projects described by Stinnett-Donnelly and colleagues included both a resident physician and a faculty physician champion. Faculty engagement in these projects is a critical resource that should not be overlooked. Since the modern concepts of value have emerged relatively recently and most faculty members were not exposed to these concepts during their training, this can be a real challenge, as it has been for QI as well. ${ }^{23}$

One of us (BMW) has some experience with treating faculty and residents as co-learners, both as a way to engage residents and also build capacity among faculty for project supervision and teaching. ${ }^{24}$ This win-win scenario creates a sense of priority for high-value care for residents when they work alongside their faculty mentors on projects. We have also found, similar to the Vermont experience, that the tandem of residents, who bring their insights into the workflows and workarounds of the current state of the system, and faculty, who can take advantage of existing relationships with institutional stakeholders and the front line to open doors and enable change, is particularly effective when it comes to leading successful high-value care projects.

For organisational leaders to support faculty engagement, institutions will need to create leadership roles and pathways in high-value care, demonstrating these activities as a viable pathway towards academic and/or medical centre promotion. For example, a few institutions have now created value management offices and chief value officers. ${ }^{25}$

\section{CONCLUSION}

We definitely need front-line engagement to foster a bottom-up approach, but it has to be top-down enabled to really make it work. Organisational leadership can support high-value care initiatives through clearly messaging endorsement and support, investing in data and resource infrastructure, and promoting faculty engagement in this work. 
Author affiliations

${ }^{1}$ Department of Medicine, University of California at

San Francisco, San Francisco, California, USA

${ }^{2}$ Center for Healthcare Value, University of California at

San Francisco, San Francisco, California, USA

${ }^{3}$ Costs of Care, Boston, Massachusetts, USA

${ }^{4}$ Division of General Internal Medicine, Sunnybrook Health

Sciences Centre, Toronto, Ontario, Canada

${ }^{5}$ Department of Medicine, University of Toronto, Toronto,

Ontario, Canada

${ }^{6}$ Department of Medicine, Centre for Quality Improvement and

Patient Safety, University of Toronto, Toronto, Ontario, Canada

Competing interests None declared.

Provenance and peer review Commissioned; internally peer reviewed.

\section{REFERENCES}

1 Korenstein D. Charting the route to high-value care: the role of medical education. JAMA 2015;314:2359-61.

2 Institute of Medicine. Best care at lower cost: the path to continuously learning health care in America. Washington DC: National Academies Press, 2012.

3 Weinberger SE. Providing high-value, cost-conscious care: a critical seventh general competency for physicians. Ann Intern Med 2011;155:386-8.

4 Levy AE, Shah NT, Moriates C, et al. Fostering value in clinical practice among future physicians: time to consider COST. Acad Med 2014;89:1440.

5 Stinnett-Donnelly JM, Stevens PG, Hood VL. Developing a high value care programme from the bottom up: a programme of faculty-resident improvement projects targeting harmful or unnecessary care. BMJ Qual Saf 2016;25:901-8.

6 Gupta R, Arora VM. Merging the health system and education silos to better educate future physicians. JAMA 2015;314:2349-50.

7 McMillan JA, Ziegelstein RC. Implementing a graduate medical education campaign to reduce or eliminate potentially wasteful tests or procedures. JAMA Intern Med 2014;174:1693-93.

8 Moriates C, Shah N. Creating an effective campaign for change: Strategies for teaching value. JAMA Intern Med 2014;174:1693-5.

9 Reed JE, Card AJ. The problem with Plan-Do-Study-Act cycles. BMJ Qual Saf 2015. Published Online First 23 Dec 2015. doi:10.1136/bmjqs-2015-005076

10 Caring WiselyTM|UCSF Center for Health Care Value. http:// healthvalue.ucsf.edu/caring-wisely (accessed 11 Dec 2015).

11 Choosing Wisely An Initiative of the ABIM Foundation. http:// www.choosingwisely.org/ (accessed 7 Oct 2013).
12 Levinson W, Kallewaard M, Bhatia RS, et al. "Choosing Wisely": a growing international campaign. BMJ Qual Saf 2015;24:167-74.

13 Moriates C, Mourad M, Novelero M, et al. Development of a hospital-based program focused on improving healthcare value. J Hosp Med 2014;9:671-7.

14 Feldman LS. Choosing wisely ${ }^{\circledR}$ : things we do for no reason. J Hosp Med 2015;10:696.

15 Breu AC, Theisen-Toupal J, Feldman LS. Serum and red blood cell folate testing on hospitalized patients. J Hosp Med 2015;10:753-5.

16 Morden NE, Colla CH, Sequist TD, et al. Choosing wisely the politics and economics of labeling low-value services. N Engl J Med 2014;370:589-92.

17 Grady D, Redberg RF, Mallon WK. How should top-five lists be developed? what is the next step? JAMA Intern Med 2014;174:498-9.

18 Kotter JP. Leading change: why transformation efforts fail. Harv Bus Rev 2007. https://hbr.org/2007/01/leadingchange-why-transformation-efforts-fail (accessed $11 \mathrm{Dec}$ 2015).

19 Kawamoto K, Martin CJ, Williams K, et al. Value Driven Outcomes (VDO): a pragmatic, modular, and extensible software framework for understanding and improving health care costs and outcomes. JAMIA 2015;22: 223-35.

20 Clarke R, Hackbarth AS, Saigal C, et al. Building the infrastructure for value at UCLA: engaging clinicians and developing patient-centric measurement. Acad Med 2015;90:1368-72.

21 Ioannidis JA. Appropriate vs clinically useful diagnostic tests. JAMA Intern Med 2013;173:1607-9.

22 Chen YA, Gray BG, Bandiera G, et al. Variation in the utilization and positivity rates of CT pulmonary angiography among emergency physicians at a tertiary academic emergency department. Emerg Radiol 2015;22:221-9.

23 Wong BM, Etchells EE, Kuper A, et al. Teaching quality improvement and patient safety to trainees: a systematic review. Acad Med 2010;85:1425-39.

24 Wong BM, Goguen J, Shojania KG. Building capacity for quality: a pilot co-learning curriculum in quality improvement for faculty and resident learners. J Grad Med Educ 2013;5:689-93.

25 Kaplan RS, MacLean CH, Dresner A, et al. Health care providers need a value management office. Harv Bus Rev 2015. https://hbr.org/2015/12/health-care-providers-need-a-valuemanagement-office (accessed 11 Dec 2015). 